\title{
A RECEPÇÃO DO TEXTO LITERÁRIO NO ENSINO: UMA EXPERIÊNCIA COM A POESIA
}

\section{The reception of literary text in class: an experience with poems}

\author{
Alice Áurea Penteado Martha ${ }^{1}$
}

\section{Resumo}

Após anos de discussão a respeito de leitura e leitura do texto literánio, sabemos que o professor ainda sente insegurança quanto à forma de trabalhar com a literatura em sala de aula. Como realizar o trabalho com um objeto de natureza extremamente livre, no caso, a literatura, em uma instituição marcada por normas e exigências que, por mais democrática e liberadora que se proponha ser, não consegue se desvencilhar de questões de caráter burocrático e de suas ligações com a ordem estabelecida?A situação parece se complicar quando o texto se apresenta em forma de poesia, especialmente em razão dos elementos estruturadores do gênero. Existem muitas formas de entrada em uma obra literária; entretanto, o professor deve estar sempre atento àquelas que permitam a participação ativa do leitor no processo de leitura, pois o texto literário compõe-se de hiatos, indeterminações, que devem ser preenchidos no ato de ler. A partir desse pressuposto, pretendemos, primeiramente, sistematizar os níveis de leitura da recepção do texto literário no ensino, propostos pelo educador alemão Hans Kügler: Leitura primária; Constituição coletiva do significado e Modos secun dáriosdeler. Em seguida, observaremos, a partir do poema O trovador, de Mário de Andrade, como podemos trabalhar, na prática, esses diferentes níveis da recepção do texto literário.

Palavras-chave: Ensino de Literatura; Recepção; Poesia.

Doutora em Letras, Professora da disciplina Literatura e Ensino, no Programa de Pós-graduação em Letras da Universidade Estadual de Maringá. - apmartha@uol.com.br 


\section{Abtract}

In the wake of many years of discussions on reading and on the reading of the literary text, it is a fact that the teacher finds himself/herself unsure about his/ her manner of dealing with literature in the classroom. How may one deal with such a free issue as literature within the context of an institution fraught with rules and demands? How may one deal with such an institution, streaming high proposals of democracy and freedom, butfailing to untie itself from bureaucratic traits and links with the establishment?Owing to the genre's structure, the issue is more complex when the poetic text is contemplated. Although there are many types of introductions to a literary work, the teacher should be aware with regard to modes that favor the active participation of the reader during the reading process. Actually, the literary text is made up of gaps and indeterminations that must be filled during reading process. Accordingly we first intend to systematize the reading reception levels of the literary text in the classroom according to the German educator Hans Kügler in his books First Reading, CollectiveConstitution of Meaning and Secondary Reading Manners. Further, an analysis of Mario de Andrade's poem $\mathrm{O}$ trovador [The singer] will be provided to show the manner these different levels of the reception literary text could be developed.

Keywords: Teaching of Literature; Reception; Poetry.

\section{A recepção do texto literário}

Após anos de discussão a respeito de leitura e leitura do texto literário, sabemos que o professor ainda sente insegurança quanto à forma de trabalhar com a literatura em sala de aula. Como realizar o trabalho com um objeto de natureza extremamente livre, no caso, a literatura, em uma instituição marcada por normas e exigências que, por mais democrática e liberadora que se proponha ser, não consegue se desvencilhar de questões de caráter burocrático e de suas ligações com a ordem estabelecida?A situação parece se complicar quando o texto se apresenta em forma de poesia, especialmente em razão dos elementos estruturadores do gênero. Posto em situação de risco, frente a um objeto que o instiga, o professor indaga o que fazer em texto marcado por dificuldades que se materializam em rimas, ritmo, versos isométricos, heterométricos e outros elementos complicadores? Existem muitas formas de entrada em uma obra literária; entretanto, o professor deve estar sempre atento àquelas que permitam a participação ativa do leitor no processo de leitura, pois o texto literário compõe-se de hiatos, ou espaços vazios, que devem ser preenchidos no ato de ler.

A partir desse pressuposto, pretendemos, em um primeiro momento, sistematizar os níveis de leitura da recepção do texto literário no ensino, pro- 
postos pelo educador alemão Hans Kügler: Leitura primária; Constituição coletiva do significado e Modos secundários de ler. Isto posto, procuraremos observar, a partir do poema $\mathrm{O}$ trovador, de Mário de Andrade, como se pode trabalhar, na prática, esse diferentes níveis da recepção do texto literário. 0 texto de Hans Kügler (1978), O ensino da literatura hoje - por quê e como?, permanece inédito, circulando apenas em tradução livre, feita por Carlos E. Fantinati, da UNESP/SP.

Na primeira fase de leitura, denominda Leitura primária, a proposta do educador alemão potencializa o momento do prazer no ato de ler, possibilitando a compreensão do texto, que é, para ele, o autoconhecimento, ou seja, o sujeito que compreende, percebe, junto com o objeto da percepção, a si mesmo. Nessa fase, Kügler destaca três momentos. O primeiro é a leitura não duplicada, quando o leitor vê o texto como se este tivesse sido elaborado apenas para ele, recusando-se a duplicá-lo; concretiza-o de acordo com suas necessidades e vivências e, iniciando o processo de formação da ilusão, vive e experiencia as situações representadas, tornando-se co-produtor do mundo ficcional. A partir daí, ocorre o que Kügler denomina Projeção e auto-inserção simulativa, etapa em que o leitor simula e desempenha papéis, vivenciando as ações no espaço da ilusão. Observa-se, então, a ocorrência de duas formas de personalização do texto: o deslocamento e a condensação. Na primeira, 0 leitor ocupa totalmente o cenário ficcional, descartando todas as outras implicações não pessoais, o que pode ofuscar sua capacidade de reflexão. Nesse momento, o leitor acredita que todos os acontecimentos textuais têm ligação estreita e exclusiva com suas necessidades e emoções e, segundo o educador alemão, embora seja um instante importante do contato entre leitor e texto, é necessário que o leitor passe rapidamente para a etapa seguinte, sob pena de perder-se em considerações extremamente pessoais, inviabilizando as múltiplas possibilidades de leitura oferecidas pelo texto literário; na condensação, entretanto, o mundo ficcional é exposto à reflexão do leitor, que o reconhece e o condensa em significado articulado, ou seja, ele reconhece que aquele texto não trata, exclusivamente, de suas emoções, mas das vivências do ser humano. Inicia-se, assim, o processo de Ruptura da formação da ilusão, intermediário entre a Leitura primária e a Constituição coletiva do significado.

Nesse momento, o leitor deixa a esfera do individual e começa a refletir sobre as múltiplas possibilidades de leitura do texto, juntamente com seus colegas, iniciando-se a $2^{\text {a }}$ fase, denominada Constituição coletiva do significado. $O$ trabalho passa a ser coletivo, o que parece ser ideal para a situação de sala de aula; é o momento em que o leitor pode confrontar suas experiências subjetivas de leitura com as experiências de outros leitores e, com isso, o processo acaba adquirindo uma opinião pública, ainda que limitada pelo espaço escolar. Mas, é nesse momento que o leitor aprende a confron- 
tar e a discutir as possibilidades de decifração de um texto. Didaticamente, a Constituição coletiva do significado ocorre em três estágios e, embora seus limites sejam imperceptíveis aos olhos de um observador menos atento ao processo de leitura, o objetivo é chegar a uma proposta de significado: articulação da experiência de leitura; confronto com outras propostas e elaboração de perspectivas para a leitura subseqüente. Ao final desses estágios, que devem ser marcados pela discussão entre sujeitos, o leitor deverá chegar à formação de hipóteses, ponte indispensável para atingir o terceiro nível. Para Kügler, este é o momento em que há perda da ilusão do texto para mim e ocorrem tentativas de racionalização da experiência de leitura.

Já na terceira e última fase do processo, denominada Modos Secundários de Ler, o leitor poderá chegar à leitura crítica tão almejada na sala de aula. Nesse estágio, podem ser estabelecidas, finalmente, as relações entre autor/texto/leitor, entre texto e contexto como preliminares indispensáveis para atingir o patamar do processo, a leitura crítica e crítico-ideológica. Na prática, a etapa final da leitura do texto literário acaba sendo, justamente, aquela pela qual, normalmente, os manuais didáticos têm proposto iniciar o estudo de textos com exercícios supostamente de compreensão e interpretação. E, em níveis mais adiantados, esses manuais elaboram todo um aparato histórico, situando autor e obra em dado momento cultural, de modo que o leitor absorva, equivocadamente, a concepção de que o texto existe e se mantém em determinado período histórico-literário, comprometendo o processo de atualização das obras literárias, tarefa dos receptores.

\section{A experiência com o poema}

Proposto para o ensino médio, o trabalho com o poema O trovador, de Mário de Andrade, inicia-se pela Leitura primária. Na sala de aula, distribuído o texto, solicitamos aos alunos que o leiam silenciosamente para que a leitura cumprisse sua função, a partir do questionamento de cada um: o que significa este texto para mim? Nesse momento de interação particular, silenciosa e afetiva entre dois sujeitos, não há necessidade de duplicação de leitura; em outras palavras, devemos respeitar esse processo estritamente pessoal para que ocorra realmente a formação da ilusão e os leitores possam projetar seus desejos e representações no espaço lírico e, a partir do deslocamento, personalizar definitivamente a leitura. Sob esse aspecto, o poema de Mário de Andrade pode conduzir a sensações, emoções e sentimentos muito caros aos adolescentes, leitores virtuais para a aplicação desta proposta. É o momento em que eles poderão acreditar que o texto atende apenas às suas necessidades, aos seus anseios, refletindo: Eu já senti isso! Eu tenho muita solidão! Isso 
eu nunca tinha pensado! Entretanto, para a comprovação da competência de leitura, deverão deixar esse estágio, extremamente pessoal, e passar à condensação, ou seja, começar a refletir sobre outros significados mais abrangentes, finalizando a compreensão afetiva e silenciosa da leitura primária. O que há de diferente no processo?, poderá indagar alguém. No processo, nada, pois, como se pode observar, ele inicia exatamente pela já conhecida leitura silenciosa; o que deve mudar é o modo de propor, uma vez que os leitores não precisarão dizer o que pensaram sobre o texto. Afinal, esse momento é, exclusivamente, dele. Uma das vantagens é que nem os alunos deverão dizer, nem o professor precisará ouvir, aquelas conhecidas e vazias manifestações: Gostei do texto, porque ele me trouxe muitas coisas novas; aprendi muitas palavras difíceis e bonitas...

\section{0 trovador}

Mário de Andrade

Sentimentos em mim do asperamente dos homens das primeiras eras...

As primaveras do sarcasmo

intermitentemente no meu coração arlequinal..

Intermitentemente...

Outras vezes é um doente, um frio

Na minha alma doente como um longo som redondo...

Cantabona!... Cantabona!...

Dlorom...

Sou um tupi tangendo um alaúde.

(Paulicéia desvairada, 1922)

Ao iniciar o processo de ruptura da formação da ilusão, os leitores deixam a esfera do individual e iniciam a reflexão sobre as múltiplas possibilidades de leitura do poema. Na prática, solicitamos o levantamento do material lingüístico do texto, de modo a sistematizar e exercitar conhecimentos adequados ao nível dos leitores, para que a decifração do texto não permaneça apenas no patamar do conteúdo. É o momento em que destacamos, no processo da leitura, a maneira pela qual a mensagem é construída, aspecto considerado fundamental por Antonio Candido (1989, p. 115), ao tratar do poder humanizador da literatura: [...] o conteúdo só atua por causa da forma, e a forma traz em si, virtualmente, uma capacidade de humanizar devido à coerên cia mental que pressupõe e que sugere.

Iniciando o levantamento do material pela compreensão de seu estrato gráfico, levamos os alunos à observação da pontuação do texto, 
que apresenta um nítido predomínio do caráter subjetivo: em 10 versos são anotadas 5 reticências, 1 vírgula e 3 exclamações, o que corrobora 0 tom entre sentimental e sarcástico que perpassa o poema, nutrido, por um lado, pela presença enfática do eu poético: em mim, no meu coração, na minha alma, sou um tupi e, por outro, pelo reconhecimento da origem de uma das vertentes de sua poesia: primaveras do sarcasmo.

No que se refere à métrica, podemos constatar que os versos têm a medida da emoção, liberada pelo inconsciente; quanto à rima, também não podemos conformá-la à tradição, pois o que nos salta aos olhos é a exploração da fantástica sonoridade das palavras. Mas há a ocorrência de algumas rimas internas, como primaveras / primeiras eras; intermitentemente / doente / doente / doente. No mais, as assonâncias e aliterações, valorizando o som e a melodia de cada palavra: sentimentos em mim do asperamente; intermitentemente; doente; longo som redondo; cantabona; dlorom. Além do aspecto da dificuldade, veiculado pela nasalidade dos sons, observamos a ressonância delas, como se vibrassem no inconsciente, atingindo como ondas sonoras o exterior do indivíduo.

O ritmo do poema valoriza o poder sugestivo, associativo, simbólico, universal, musical da palavra em liberdade, conforme apregoa 0 Prefácio interessantíssimo, exemplificando ainda o que Mário de Andrade denomina sistema melódico de compor, onde sons consecutivos apresentam pensamento inteligível: Sentimentos em mim do asperamente / dos homens das primeiras eras... / Outras vezes é um doente, um frio / na minha alma doente como um longo som redondo...

Para os leitores-alvo, o vocabulário é extremamente simples, destacando-se apenas o termo cantabona, utilizado duas vezes no mesmo verso. Sem significado no português nem no italiano, como se poderia supor, a palavra parece ser mais uma valorização de sons, uma brincadeira sonora do eu poético. O termo alaúde, por sua vez, chama a atenção porque surge fora de seu contexto, ligando-se muito mais ao trovador que ao tupi que o tange no texto. É interessante observarmos ainda 0 emprego do verbo tanger que, por sua forma de gerúndio, acaba significando tanto tocar instrumentos quanto ressoar e ecoar. O segundo sentido se deve ao som de eco da forma gerundiva do verbo.

É significativa, e deve ser levantada pelos leitores, a semelhança fônica e mesmo de sentido entre a palavra primavera e a expressão primeiras eras, provocando, inclusive, uma anáfora na construção do poema. Primavera origina-se do latim primo vere, que quer dizer no começo do verão e, em sentido figurado, significa época primeira, aurora, aproximando-se da significação de primeiras eras. O caráter alegre e colorido veiculado pelo vocábulo primavera se desfaz, no entanto, com a expres- 
são que o caracteriza - de sarcasmo. A antítese evidencia a contradição latente em todo o poema.

A expressão coração arlequinal, além de evocar a já conhecida significação do caráter colorido e alegre da paulicéia desvairada, pode revelar um aspecto importante do texto, a fragmentação interior do ser. A partir do trabalho com dicionários, os leitores poderão compreender que o termo coração significa o homem interior, a vida afetiva, os sentimentos, a subjetividade enfim; arlequinal, vocábulo que o caracteriza, provém de arlequim, personagem da antiga comédia italiana que tinha por intuito a diversão do público, ridicularizando a sociedade burguesa. Significa, ainda, bufão, elemento que encarna a dualidade de todo ser, uma vez que dá a fatos banais um tom grave e um tom de galhofa a acontecimentos verdadeiramente importantes.

A sintaxe insólita do poema revela aproximações do poeta com as vanguardas estéticas do início do século: a escrita automática do surrealismo, por exemplo, pode explicar a estranha construção dos versos Sentimentos em mim do asperamente / dos homens das primeiras eras... Se tais versos não possuem organização sintática lógica e usual, também não se ligam tradicionalmente aos seguintes, que se apresentam como fragmentos soltos. Cabe aos leitores a tarefa de amarrá-los significativamente.

A fragmentação, o caráter estranho do discurso se consuma notadamente pela supressão do verbo em sua construção. Ao longo de vários versos, há apenas expressões nominais, como é o caso dos nove primeiros que constituem o bloco inicial do poema. Embora apareça uma forma verbal - é - esta se caracteriza também como nominal, descartável, portanto. Com a supressão do verbo, as palavras fluem livremente, em sucessão e associações mais livres e o substantivo acaba ganhando maior intensidade, configurando o que se pode chamar de ambigüidade léxica. A alteração nas funções das classes de palavras no poema provoca conflito e ambigüidade em seu significado. A substantivação do advérbio asperamente, por exemplo, concretiza o rude, o áspero do primitivismo poético. A palavra doente, repetida, ora é substantivo - um doente - ora é adjetivo - alma doente. A repetição do advérbio intermitentemente também é significativa uma vez que sublinha o modo como os sentimentos do passado emergem no espírito do poeta: fluem de modo descontínuo. Essa descontinuidade do fluxo do pensamento materializa-se, inclusive, pela pontuação extremamente subjetiva e pela camada sonora do poema, que, predominantemente nasal, reflete a dificuldade com que as idéias emergem do inconsciente. 
Quanto ao título, O trovador, é, sem dúvida, uma alusão à retomada, no poema, de velhos temas e até mesmo de alguns processos de composição. Proveniente do provençal trobador e do francês trouvère, o termo relaciona-se intimamente à práxis poética na medida em que designava na Idade Média, o poeta completo, responsável pela letra e melodia da composição. As produções dos trovadores eram cantadas com acompanhamento de instrumentos musicais. Por esta razão, o trovador de Mário de Andrade tange um alaúde, instrumento de cordas, de origem oriental, que fazia o acompanhamento musical das cantigas do trovador moçárabe. Acompanhado de um determinante /o/, o título sugere algo conhecido do leitor, carreando para o interior do texto as ressonâncias da lírica trovadoresca. Mas se o título parece tornar o assunto familiar, o último verso promove a estranheza e o insólito. A incongruência se consuma no final do poema, quando os leitores, preparados para ouvir o trovador, vêem tal expectativa se romper com a presença inusitada de um tupi tangendo um alaúde. Neste verso, outra imagem insólita: o tupi utilizando-se de um instrumento musical do trovador. No fluxo do inconsciente, portanto, passado e presente se mesclam.

Levantados os elementos dos vários campos de construção do poema - gráfico, fônico, lexical, sintático e semântico, passamos à terceira etapa do processo proposto por Kügler, denominada Modos secundários de ler, momento que devemos chegar à leitura crítica tão almejada pelos professores. Tendo sempre em vista os elementos levantados na Constituição coletiva dos significados, consideramos a construção do poema que, como um todo, caracteriza-se pela ruptura, tanto da tessitura lingüística como das regras gramaticais e da ordenação do discurso, o que comprova que a lírica moderna aspira à dissonância e à incongruência como forma de expressão, inclusive como exasperação de formas de protesto veiculadas em estéticas anteriores. Como o próprio título do poema pressupõe, é possível a recuperação de alguns caracteres da poesia trovadoresca no poema modernista, com o evidente estranhamento na retomada desses recursos, como o dobre dos versos: As primaveras do sarcasmo / intermitentemente no meu coração arlequinal... / Intermitentemente... / Outras vezes é um doente, um frio / na minha alma doente como um longo som redondo...

Além do dobre, há referências diretas tanto à cantiga de escárnio, onde a sátira à sociedade e às instituições era artificiosamente arquitetada por meio da ironia e do sarcasmo - primaveras do sarcasmo como à cantiga de amor, ou ao sentimentalismo e emotividade dela decorrentes. De modo geral, observamos uma recuperação de toda poesia valorizadora da sensibilidade, das emoções e da música, desde a lírica 
trovadoresca, passando pelo romantismo e pelo simbolismo. Tal recuperação se dá com a marca da ironia, pois o poeta se vale do que é familiar aos leitores, a música e a emoção na poesia, para, depois, jogálos no mundo do insólito, onde o selvagem atua com o instrumento da cultura, ou seja, o tupi tange o alaúde.

A leitura do poema pode levar-nos a pensar o texto em duas partes, estrutura dual que reflete o movimento em que se debate $0 \mathrm{eu}$ poético, entre passado histórico e o primitivismo do presente, entre passividade e atividade, entre o inconsciente e o consciente. Nos nove (9) primeiros versos, o eu poético libera seu inconsciente, projetando fragmentos do passado sobre a práxis poética do presente, deixa fluir, intermitentemente, as emoções, as sensações ali guardadas. É um bloco caracterizado pela imobilidade e pelo fluxo descontínuo do pensamento. 0 predomínio das expressões nominais, a pontuação excessiva e a camada sonora dos versos configuram, no plano material do poema, a dificuldade, a descontinuidade com que as imagens e as sensações do passado emergem do inconsciente para o consciente.

O último verso, Sou um tupi tangendo um alaúde, opõe-se aos nove primeiros não só pelo inusitado, pela quebra de expectativa, como também pelo dinamismo, pela consciência e mesmo pela constatação a que o eu poético chega de que sua obra, na verdade, se constrói pelo jogo entre passado e presente, entre trovadorismo e primitivismo (corrente do modernismo brasileiro), entre cultura e natureza, entre consciência e inconsciência. A superação do conflito se verifica pela união dos opostos: tupi, o dado da modernidade, elemento do novo mundo, une-se ao instrumento musical, alaúde, representante da tradição lírica universal.

Concluindo, no terceiro nível de leitura proposto por Kügler, os alunos chegarão, finalmente, às relações entre autor/ texto/contexto, considerando, por exemplo, como Mário de Andrade é valorizado nos meios acadêmicos, em função das inovações e transgressões que legou à literatura brasileira. No poema estudado, alinham-se as propostas inovadoras de Mário; condensam-se as formas de transgressão e ruptura ao lado da postura primitivista-surrealista-expressionista, essencialmente neoromântica. A recuperação do passado pode ser imediatamente percebida pela presença do trovador, símbolo da lírica medieval, bem como pela retomada de recursos característicos da estética trovadoresca; por outro lado, a aspiração à modernidade se verifica pelo modo dissonante e inovador como os elementos do passado emergem no texto. 


\section{Referências}

ANDRADE, Mário de. A costela do grão cão. In: . De paulicéia desvairada a Café (Poesias Completas). São Paulo, SP: Círculo do Livro, 1986.

CANDIDO, Antonio. Direitos humanos e literatura. In: FESTER Antonio C. Ribeiro (Org.). Direitos humanos e ... São Paulo, SP: Brasiliense, 1989.

KÜGLER, Hans. Literatur un kommunikation: Stuttgart, Ernst Klett. 1978. Tradução de Carlos E. Fantinati. (Texto digitado)

Recebido em: 21/04/2005. Aprovado em: 20/06/2005. 